\title{
A Comparative Passivation Study for InAs/GaSb Pin Superlattice Photodetectors
}

\author{
Omer Salihoglu, Abdullah Muti, and Atilla Aydinli
}

\begin{abstract}
In the quest to find ever better passivation techniques for infrared photodetectors, we explore several passivation layers using atomic layer deposition (ALD). We compare the impact of these layers on detectors fabricated under same conditions. We use ALD deposited $\mathrm{Al}_{2} \mathrm{O}_{3}, \mathrm{HfO}_{2}, \mathrm{TiO}_{2}, \mathrm{ZnO}$, plasma enhanced chemical vapor deposition deposited $\mathrm{SiO}_{2}$, $\mathrm{Si}_{3} \mathrm{~N}_{4}$, and sulfur containing octadecanethiol self assembled monolayer passivation layers on InAs/GaSb p-i-n superlattice diodes with an average cutoff wavelength of $5.1 \mu \mathrm{m}$. Passivated and unpassivated photodetectors compared for their electrical performances.
\end{abstract}

Index Terms - Infrared, Photodetector, InAs/GaSb, Passivation, ALD, ODT, Thiol.

\section{INTRODUCTION}

$\mathbf{F}$ INAL stage in the development of infrared photodiodes is the fabrication of a focal plane array and integrating it to a read out circuit. Commercially available read out integrated circuits (ROICs) require the FPA to have high dynamic resistance area product at zero bias (R0A) which is directly related to dark current of the detector. Dark current arises from bulk and surface contributions. Recent band structure engineering studies significantly suppressed the bulk contribution of the type-II superlattice infrared photodetectors [1]-[3], but surface related leakage currents can still be a dominant part of the dark current, short circuiting the gains from band gap engineering. In the standard approach to fabrication of a diode pixel, mesa definition processes lead to abruptly terminated mesa side walls which can cause band bending near the mesa walls resulting in carrier accumulation. Freshly etched mesa side walls typically contain dangling bonds, inversion layers and interfacial traps [4]. These defects in the otherwise perfect crystal can create surface leakage channels. In order to overcome surface leakage currents, various passivation methods such as chalcogenide treatment [5], deposition of dielectric layer [6]-[8], polymer coating [9], overgrowth with wide bandgap material [10] have been used. Ammonium sulfide $\left(\left[\mathrm{NH}_{4}\right]_{2} \mathrm{~S}\right)$, sodium sulfide $\left(\mathrm{Na}_{2} \mathrm{~S}\right)$, thioacetamide $\left(\mathrm{C}_{2} \mathrm{H}_{5} \mathrm{NS}\right)$, zinc sulfide $(\mathrm{ZnS})$ and self assembled monolayers (SAMs) terminated with sulphur heads i.e. octodeconothiol (ODT)

Manuscript received April 8, 2013; revised May 10, 2013; accepted June 4, 2013. Date of publication June 10, 2013; date of current version June 28, 2013.

The authors are with the Department of Physics, Bilkent University, Ankara 06800, Turkey (e-mail: omer@fen.bilkent.edu.tr; muti@fen.bilkent.edu.tr; aydinli@fen.bilkent.edu.tr).

Color versions of one or more of the figures in this paper are available online at http://ieeexplore.ieee.org.

Digital Object Identifier 10.1109/JQE.2013.2267553 solutions have been used [11] as sources for chalcogenide treatments. Sulphur in these solutions satisfies the dangling bonds and "cleans" the conductive native oxides at the surface by replacing oxygen atom with sulfur atom. Sulphurization is a very effective method and it can be applied very easily by just dipping samples in a sulphur containing solution. Although it is very effective, almost all sulphur solutions lack long term stability layer except for ODT SAM passivation [11], and they do not protect against environmental effects. Furthermore during the treatment, they can damage the superlattice material leading to diminished optical performance. Dielectric passivation is a widely used method. It is thought to satisfy the dangling bonds and create a potential barrier at the etched walls to limit carrier mobility on the surface and create a stable protective layer. Plasma enhanced chemical vapor deposition (PECVD) is used to deposit thin layer of silicon dioxide $\left(\mathrm{SiO}_{2}\right)$, which is a widely used industry standard dielectric material for superlattice detector passivation. Alternatively, atomic layer deposition (ALD) can be used to deposit conformal and high-k dielectric layers such as $\mathrm{Al}_{2} \mathrm{O}_{3}$ as a passivation layer. ALD technique is a plasma free and low temperature process, eliminating the possibility of damage to the superlattice surface due to ion bombardment and ALD self cleans the native oxides on the surface by replacing surface metal atoms with $\mathrm{Al}$ atoms due to lower Gibbs free energies of formation of $\mathrm{Al}_{2} \mathrm{O}_{3}$ [12]. Organic polymers such as polyimide and SU8 are also used as passivation layers. Spin coating of these polymers result in damage free passivation layers. However, spin coating may not create a conformal layer and these polymers usually require around $180{ }^{\circ} \mathrm{C}$ to hard bake.

Above mentioned studies have been done by many different groups. This makes it very difficult to compare how effective different passivation methods are since different fabrication recipes and different epi structures are used. In this paper, we will compare the result of different passivation techniques which are done under same conditions, same epitaxial structure and same fabrication processes. We will compare the for electrical performances of type-II superlattice pin photodetectors to determine the effectiveness of ODT SAM passivation, PECVD grown $\mathrm{SiO}_{2}$ and $\mathrm{Si}_{3} \mathrm{~N}_{4}$ passivation, ALD grown $\mathrm{Al}_{2} \mathrm{O}_{3}, \mathrm{HfO}_{2}, \mathrm{TiO}_{2}$ and $\mathrm{ZnO}$ passivation. We previously worked on ODT SAM and $\mathrm{Al}_{2} \mathrm{O}_{3}$ passivation and $\mathrm{SiO}_{2}$ and $\mathrm{Si}_{3} \mathrm{~N}_{4}$ passivation along with others, but $\mathrm{HfO}_{2}, \mathrm{TiO}_{2}$ and $\mathrm{ZnO}$ passivation has never been studied before for $\mathrm{InAs} / \mathrm{GaSb}$ superlattice passivation. ODT SAM contains a reactive sulfur head $(\mathrm{S}-\mathrm{H})$ at the end of the 18 carbon long chain. Sulphur atom at the end of the carbon chain of the thiol bonds with 


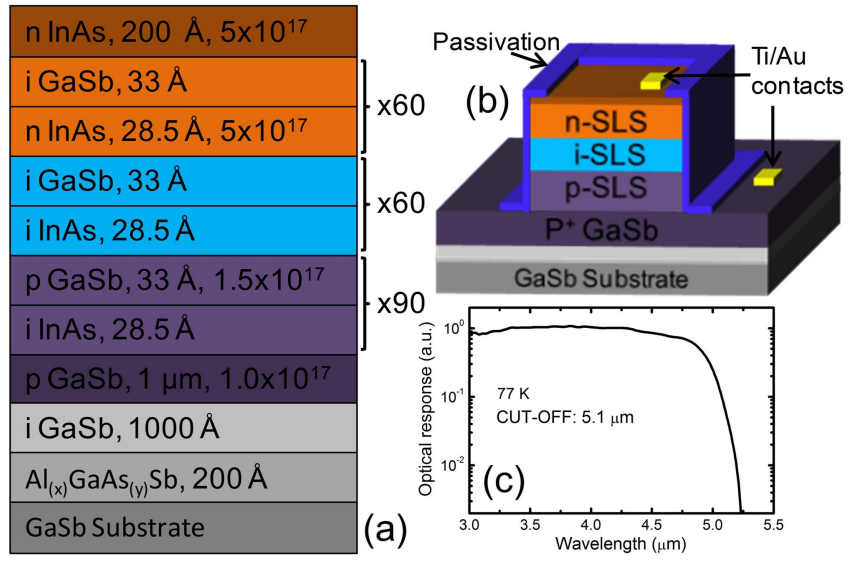

Fig. 1. (a) Periodic structure of the p-i-n design superlattice crystal with corresponding thicknesses and doping concentrations. (b) Schematic cross section of the InAs/GaSb SL p-i-n photodiode structure. (c) Measured cut-off wavelength of the SL structure.

surface atoms, to protect the surface from oxidation while at the same time satisfying dangling bonds. ODTs induce the exchange of oxygen atoms and sulphur atoms. They may be said to clean the surface from conductive native oxides [13], [14]. The application of thiol is easily done by dipping the sample into the thiol solution. Self assembling thiol does not damage III-V surfaces [14] and van der Waals interaction among the length of the ODT SAM chains, increases thermodynamic stability [15]. Intermolecular forces among the hydrocarbon chains lead to formation of a skin-like hydrocarbon layer of few $\mathrm{nm}$ thick, resulting in long term stable layers unlike other sulphurization techniques. $\mathrm{SiO}_{2}$ and $\mathrm{Si}_{3} \mathrm{~N}_{4}$ are both good dielectrics so they can create good carrier blockage at the surface. They provide very good protection against atmospheric aging and satisfy surface dangling bonds. $\mathrm{SiO}_{2}$ passivation has been found to be better than $\mathrm{Si}_{3} \mathrm{~N}_{4}$ passivation for type-II InAs/GaSb superlattice photodetectors [16]. In ALD growth of thin films, two gasses containing the atoms that make up the thin films are introduced into the chamber one at a time sequentially and allowed to react with the atoms of the gas previously adsorbed on the surface. With this approach precise control of thickness as well as perfect conformal coverage with large area thickness uniformity with low process temperatures and plasma free operating conditions are obtained. Considering that oxidation of exposed surfaces is almost instantaneous formation of thin layer of oxides immediately prior to passivation is unavoidable. A process that eliminates already formed thin oxide layer on the mesa side walls is sought. ALD technique is a promising approach for the passivation of III-V based photodetectors [17].

\section{EXPERIMENTAL}

The SL structure was designed for MWIR operation with design cutoff wavelength of $5 \mu \mathrm{m}$ and was grown commercially (IQE Inc. USA) with molecular beam epitaxy on a GaSb substrate. It starts with $20 \mathrm{~nm} \mathrm{Al}(\mathrm{x}) \mathrm{GaAs}(\mathrm{y}) \mathrm{Sb}$ as an insulating etch stop layer and $100 \mathrm{~nm}$ thick GaSb buffer layer, followed by $1000 \mathrm{~nm} \mathrm{GaSb}: \mathrm{Be}\left(\mathrm{p}=1.0 \times 10^{17} \mathrm{~cm}^{-3}\right) \mathrm{p}$ contact layer. Figure 1a. shows periodic structure of the p-i-n part of the superlattice crystal with corresponding thicknesses and doping concentrations. Single pixel photodetectors with mesa sizes of $100 \times 100-700 \times 700 \mu \mathrm{m}^{2}$ have been fabricated by standard lithography. Mesa-isolation of photodiodes are defined at room temperature using a chemical solution based on $\mathrm{H}_{3} \mathrm{PO}_{4} / \mathrm{C}_{6} \mathrm{H}_{8} \mathrm{O}_{7} / \mathrm{H}_{2} \mathrm{O}_{2} / \mathrm{H}_{2} \mathrm{O}$ with $200 \mathrm{~nm}$ per minute etch rate.

We chose $160^{\circ} \mathrm{C}$ as growth temperature for PECVD which was already reported as best $\mathrm{SiO}_{2}$ growth temperature for passivation purposes [7]. After setting the working temperature, we used the successful recipes that are optimized for many years. For ODT-SAM coating parameters we used the recipe from this paper [18]. For ODT passivation, the sample was immersed in $1 \mathrm{mM}$ solution of ODT (Aldrich, 99\%) in ethanol and was left in the solution for 48 hours at $60{ }^{\circ} \mathrm{C} . \mathrm{SiO}_{2}$ and $\mathrm{Si}_{3} \mathrm{~N}_{4}$ films were coated in PlasmaLab 8510C reactor at $160{ }^{\circ} \mathrm{C}$ and the process was carried out under the pressure of 0.5 Torr and RF power of $9 \mathrm{~W}$. Flow rates were $180 \mathrm{sccm}$ $\mathrm{SiH}_{4}\left(\% 2\right.$ in $\left.\mathrm{N}_{2}\right), 225 \mathrm{sccm} \mathrm{N} \mathrm{N}_{2} \mathrm{O}$ for $\mathrm{SiO}_{2}$ and $45 \mathrm{sccm} \mathrm{NH}$ for $\mathrm{Si}_{3} \mathrm{~N}_{4}$. Final thickness of the passivation layer was about $250 \mathrm{~nm} . \mathrm{Al}_{2} \mathrm{O}_{3}, \mathrm{HfO}_{2}, \mathrm{TiO}_{2}$ and $\mathrm{ZnO}$ depositions carried out in atomic layer deposition system (Savannah 100) with $150{ }^{\circ} \mathrm{C}$ as the substrate holder temperature under constant $20 \mathrm{sccm} \mathrm{N} \mathrm{N}_{2}$ gas flow. Growth of thin films have been done by delivering $0.015 \mathrm{~s}$ water vapor $\left(\mathrm{H}_{2} \mathrm{O}\right)$ and related precursor gas pulses into the chamber in a sequential manner. A wait time of $20 \mathrm{~s}$ was added after each pulse to ensure surface reactions to take place. $0.015 \mathrm{~s}$ trimethylaluminum (TMA), $0.15 \mathrm{~s}$ tetrakis (dimethylamido) hafnium (TDMAHf), $0.15 \mathrm{~s}$ tetrakis (dimethylamido) titanium (TDMATi) and $0.2 \mathrm{~s}$ dimethylzinc (DMZn) precursor gas pulses used for $\mathrm{Al}_{2} \mathrm{O}_{3}, \mathrm{HfO}_{2}, \mathrm{TiO}_{2}$ and $\mathrm{ZnO}$ film depositions, respectively. In Figure $1 \mathrm{~b}$ InAs/GaSb SL p-i-n photodiode is displayed schematically. Passivation layer covers all exposed sides of the mesa. Figure 1c shows measured cut-off wavelength of the designed SL structure after optical response measurements which are done at $77 \mathrm{~K}$ by using a FTIR.

\section{RESUlts AND Discussion}

Figure 2a shows the measured dark current density vs. applied bias voltage characteristics of the unpassivated and passivated $400 \times 400 \mu \mathrm{m}$ single pixel test diodes at $77 \mathrm{~K}$. Figure $2 \mathrm{~b}$ shows dynamic resistance area product (RA) vs. applied bias voltage for all photodiodes studied in this paper. Photodetectors passivated with a thin layer of $\mathrm{Al}_{2} \mathrm{O}_{3}$ shows the lowest dark current and highest dynamic resistance area product values for all bias voltages. $\mathrm{Si}_{3} \mathrm{~N}_{4}$ is clearly the worst passivation material in this group. Photodetectors with ODT passivation show almost the same electrical characteristics with $\mathrm{Al}_{2} \mathrm{O}_{3}$ passivated photodetectors up to $0.1 \mathrm{~V}$ reverse bias beyond which the slope of the dark current increases when compared with detectors that are passivated with $\mathrm{Al}_{2} \mathrm{O}_{3}$. Weak fluctuations in the ODT is suggestive of trap related leakages. Since the ODT chain is $2 \mathrm{~nm}$ long and the process is self limited, some trap states on surface of ODT layer may still affect the electrical performance of the detector at high voltages through tunneling. At $-0.1 \mathrm{~V}$ reverse bias, dark current densities are measured as $3.3 \times 10^{-8} \mathrm{~A} / \mathrm{cm}^{2}, 3.9 \times 10^{-8} \mathrm{~A} / \mathrm{cm}^{2}$, 

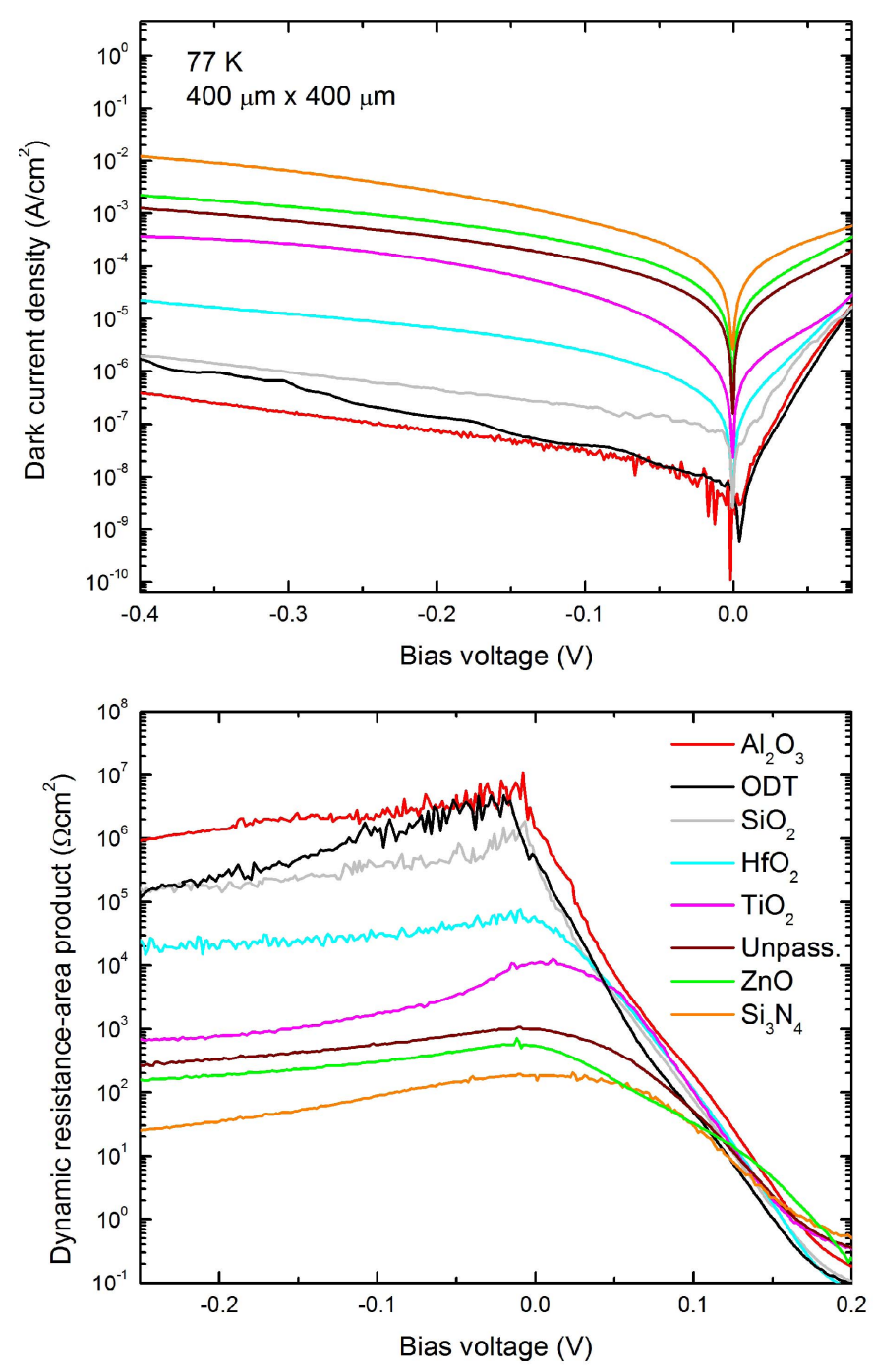

Fig. 2. (a) Dark current density vs. applied bias voltage curves for passivated and unpassivated $400 \times 400 \mu \mathrm{m}$ diodes at $77 \mathrm{~K}$. (b) Differential dynamic resistance area product vs. applied bias voltage characteristics for the diodes at $77 \mathrm{~K}$.

$2.2 \times 10^{-7} \mathrm{~A} / \mathrm{cm}^{2}, 2.5 \times 10^{-6} \mathrm{~A} / \mathrm{cm}^{2}, 3.1 \times 10^{-5} \mathrm{~A} / \mathrm{cm}^{2}$, $2.5 \times 10^{-4} \mathrm{~A} / \mathrm{cm}^{2}, 7.3 \times 10^{-4} \mathrm{~A} / \mathrm{cm}^{2}$ and $1.3 \times 10^{-4} \mathrm{~A} / \mathrm{cm}^{2}$ for the $\mathrm{Al}_{2} \mathrm{O}_{3}$, ODT, $\mathrm{SiO}_{2}, \mathrm{HfO}_{2}, \mathrm{TiO}_{2}, \mathrm{ZnO}, \mathrm{Si}_{3} \mathrm{~N}_{4}$ passivated and unpassivated diodes, respectively. These measurements yield RA product values of $2.5 \times 10^{6} \Omega \mathrm{cm}^{2}, 1.5 \times 10^{6} \Omega \mathrm{cm}^{2}$, $3.6 \times 10^{5} \Omega \mathrm{cm}^{2}, 2.8 \times 10^{4} \Omega \mathrm{cm}^{2}, 1.7 \times 10^{3} \Omega \mathrm{cm}^{2}$, $3.1 \times 10^{2} \Omega \mathrm{cm}^{2}, 8.8 \times 10^{1} \Omega \mathrm{cm}^{2}$ and $5.7 \times 10^{2} \Omega \mathrm{cm}^{2}$ for the $\mathrm{Al}_{2} \mathrm{O}_{3}, \mathrm{ODT}, \mathrm{SiO}_{2}, \mathrm{HfO}_{2}, \mathrm{TiO}_{2}, \mathrm{ZnO}, \mathrm{Si}_{3} \mathrm{~N}_{4}$ passivated and unpassivated diodes at $0.1 \mathrm{~V}$ reverse bias, respectively. To have a reliable comparison, both the epitaxial structure and the fabrication process, except for the passivation step, are kept the same for all devices in this paper. Our electrical measurements show that $\mathrm{Al}_{2} \mathrm{O}_{3}$ passivation results in lower dark current than $\mathrm{SiO}_{2}$ passivation at the same temperature. We tested the effect of passivation for mesa sizes ranging from $100 \times 100$ to $700 \times 700 \mu \mathrm{m}^{2}$ and devices with $\mathrm{Al}_{2} \mathrm{O}_{3}$ passivation show lower dark currents than devices with $\mathrm{SiO}_{2}$ passivation. Our devices with $\mathrm{SiO}_{2}$ passivation are as good as

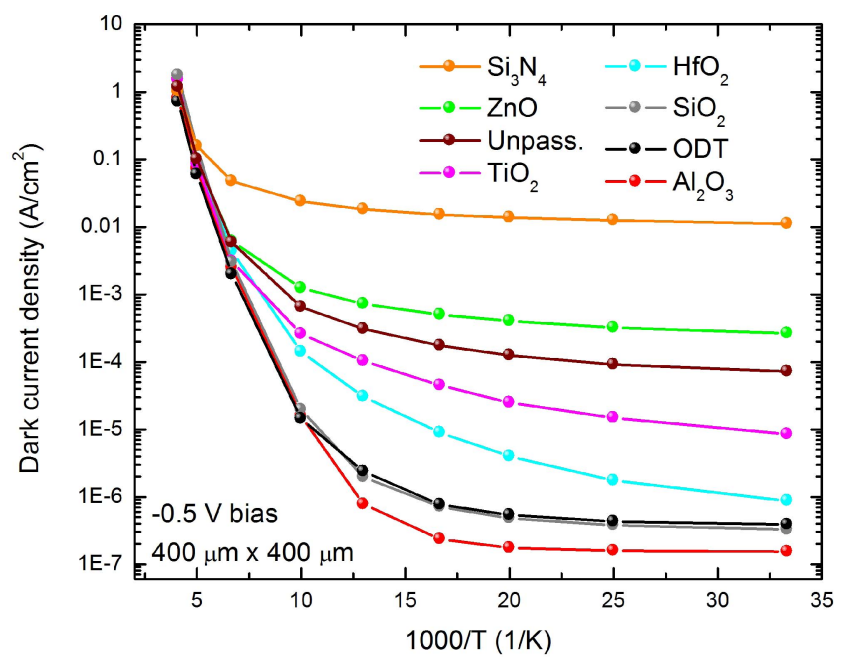

Fig. 3. Temperature dependent dark current density for unpassivated and passivated type-II InAs/GaSb superlattice $400 \times 400 \mu \mathrm{m}$ photodiodes at $-0.5 \mathrm{~V}$ bias voltage.

the state-of-the-art devices with $\mathrm{SiO}_{2}$ passivation, published in the literature [19].

Relationship between dark current densities versus inverse temperatures under $0.5 \mathrm{~V}$ reverse bias is shown in Figure 3. The temperature dependent I-V curve is dominated by diffusion current at high temperatures, generation-recombination current at mid temperatures and trap related currents at low temperatures. For temperatures lower than $70 \mathrm{~K}$, all samples are dominated by surface related trap currents which give information about quality of the passivation.

$\mathrm{Al}_{2} \mathrm{O}_{3}$ passivation results in at least an order of magnitude better performance than its closest competitor. This suggests that $\mathrm{Al}_{2} \mathrm{O}_{3}$ passivation reduces native oxides [20] eliminating surface states and preventing current flow through the surface channel. ODT and $\mathrm{SiO}_{2}$ passivated samples show almost the same performance in this voltage range. ODT passivation is associated with more trap states than $\mathrm{Al}_{2} \mathrm{O}_{3}$ passivation which dominate under higher reverse bias. Photodetectors with $\mathrm{Si}_{3} \mathrm{~N}_{4}$ and $\mathrm{ZnO}$ passivations perform worse than unpassivated photodetectors failing to reduce the existing surface states generated during the etch process but seem to introduce additional states themselves. Even though $\mathrm{ZnO}$ is a wide bandgap semiconductor with a band gap of $3.37 \mathrm{eV}$ at room temperature [21] it is well known that impurities can create states in the band gap of the thin $\mathrm{ZnO}$ film [22] reducing the barrier for surface conduction and leading to conductive surface channels. ALD deposited $\mathrm{HfO}_{2}$ and $\mathrm{TiO}_{2}$ passivation makes a better photodetector when compared with unpassivated detectors, but they are not as good as $\mathrm{Al}_{2} \mathrm{O}_{3}$ passivation. Self cleaning mechanism of the surface oxides works better in $\mathrm{Al}_{2} \mathrm{O}_{3}$ passivation due to lower Gibbs free energies of aluminum oxides for temperatures higher than $150 \mathrm{~K}$, Arrhenius type behavior has been observed for all samples which is an indication of diffusion dominated behavior. Arrhenius type behavior yielded activation energies of approximately $0.23 \mathrm{eV}$ which is close to the device band gap. Bulk diffusion limited behavior gives information about the limits of photodetector material. 


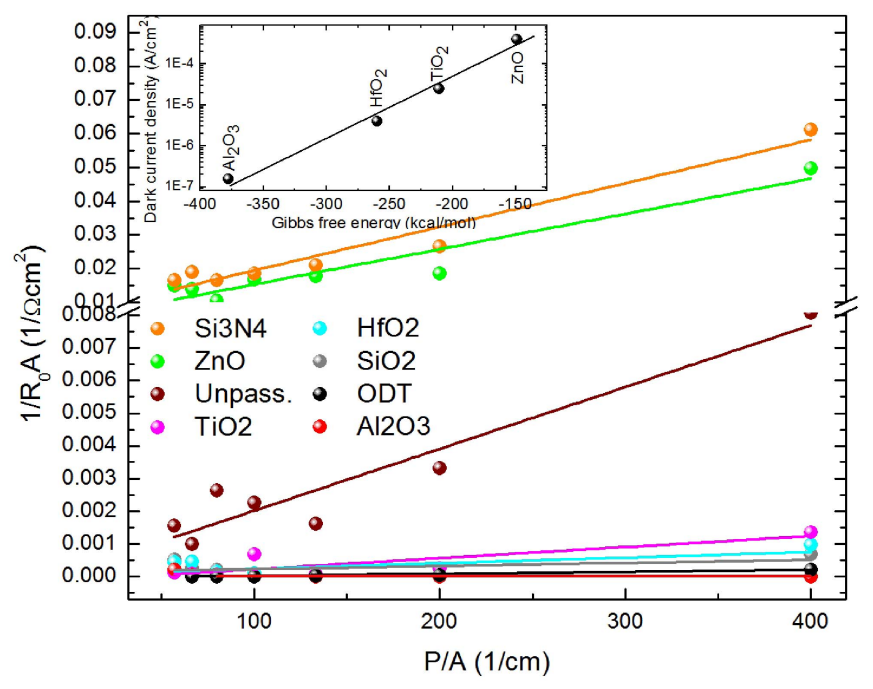

Fig. 4. Dynamic resistance-area products at zero bias vs. perimeter to area ratio at $77 \mathrm{~K}$. Inset shows dark current density vs. Gibbs free energy of formation for $\mathrm{Al}_{2} \mathrm{O}_{3}, \mathrm{HfO}_{2}, \mathrm{TiO}_{2}$ and $\mathrm{ZnO}$ at $50 \mathrm{~K}$.

$\mathrm{Si}_{3} \mathrm{~N}_{4}$ passivated detectors become diffusion dominated when the temperature is greater than $200 \mathrm{~K}, \mathrm{ZnO}, \mathrm{TiO}_{2}, \mathrm{HfO}_{2}$ passivated and unpassivated diodes become dominated by diffusion current at temperatures above $150 \mathrm{~K}$, ODT and $\mathrm{SiO}_{2}$ passivated detectors become diffusion dominated after $100 \mathrm{~K}$ and $\mathrm{Al}_{2} \mathrm{O}_{3}$ passivated detectors become diffusion dominated after $77 \mathrm{~K}$. Due to excessive surface current in the case of $\mathrm{Si}_{3} \mathrm{~N}_{4}$ and $\mathrm{ZnO}$ passivation as well as unpassivated diodes, G-R current becomes negligible.

Figure 4 shows inverse dynamic resistance area product at zero bias as a function of the perimeter to area ratio for passivated and unpassivated diodes at $77 \mathrm{~K}$. Surface and bulk contributions to the dark current can be approximated as $1 / \mathrm{R}_{0} \mathrm{~A}=\left[\left(1 / \mathrm{R}_{0} \mathrm{~A}\right)_{\text {bulk }}+\left(1 / \mathrm{r}_{\text {surface }}\right)(\mathrm{P} / \mathrm{A})\right]$. Using this equation, the surface part of the resistance-area product can be calculated from the slope of the graph. Calculated surface resistivity (rsurface) values at zero bias are $2.1 \times 10^{7} \Omega \mathrm{cm}$, $3.9 \times 10^{6} \Omega \mathrm{cm}, 1.1 \times 10^{6} \Omega \mathrm{cm}, 5.8 \times 10^{5} \Omega \mathrm{cm}$, $2.9 \times 10^{5} \Omega \mathrm{cm}, 9.5 \times 10^{3} \Omega \mathrm{cm}, 7.7 \times 10^{3} \Omega \mathrm{cm}$ and $5.2 \times 10^{5} \Omega \mathrm{cm}$ for $\mathrm{Al}_{2} \mathrm{O}_{3}, \mathrm{ODT}, \mathrm{SiO}_{2}, \mathrm{HfO}_{2}, \mathrm{TiO}_{2}, \mathrm{ZnO}$, $\mathrm{Si}_{3} \mathrm{~N}_{4}$ passivated and unpassivated photodetectors, respectively. Measurement system limitations caused noise at zero bias in some samples. This caused an increase in the uncertainty of the R0A values calculated. Inset shows dark current density vs. Gibbs free energy of formation for $\mathrm{Al}_{2} \mathrm{O}_{3}, \mathrm{HfO}_{2}$, $\mathrm{TiO}_{2}$ and $\mathrm{ZnO}$ at $50 \mathrm{~K}$. It is clear that the dark current density reduces with decreasing Gibbs free energies. Line is drawn to guide the eye. Results of Fig. 4 are also confirmed by temperature dependent $\mathrm{I}-\mathrm{V}$ measurements. ALD deposited $\mathrm{Al}_{2} \mathrm{O}_{3}$ reduces surface currents at least an order of magnitude better than other passivation materials investigated in this paper.

Good passivation should satisfy the dangling bonds, self clean the native oxides, protect the fresh surface against environmental effects. It should be also a good dielectric material to avoid introducing additional conductive channels at the surface. Surface passivation is even more critical in Type-II superlattice (T2SL) InAs/GaSb photodetectors, due to large number of very thin alternating layers. Different etch rates of InAs and $\mathrm{GaSb}$ during mesa definition lead to roughness on the mesa side walls. A conformal coating can be critical to cover all the tiny undulations on mesa side walls. Components of InAs/GaSb SL are chemically very reactive. Their surfaces are easily oxidized and a native oxide layer of several nanometers thick is quickly formed upon exposure to air. Adsorbed oxygen diffuses through the surface, reacts with $\mathrm{Ga}, \mathrm{Sb}$, In and $\mathrm{As}$ atoms then forms native oxides such as $\mathrm{Ga}_{2} \mathrm{O}_{3}, \mathrm{Sb}_{2} \mathrm{O}_{3}, \mathrm{In}_{2} \mathrm{O}_{3}$, $\mathrm{As}_{2} \mathrm{O}_{3}$ and $\mathrm{InAsO}_{3}$ [23], [24] some of which is conductive. This mechanism is responsible for the formation of additional conductive channels and consequently, leads to a large surface component of dark current. Atomic layer deposition is a conformal coating technique and the deposited layer can react with surface oxides and replace native oxides with ALD oxides, leading to so called self cleaning of the surface [25]. This makes ALD technique very useful but to have self cleaning mechanisms to work, Gibbs free energies of the ALD oxides should be lower than Gibbs free energy of the native oxides. The Gibbs free energies of $\mathrm{Ga}_{2} \mathrm{O}, \mathrm{Ga}_{2} \mathrm{O}_{3}, \mathrm{In}_{2} \mathrm{O}_{3}, \mathrm{As}_{2} \mathrm{O}_{3}$, $\mathrm{As}_{2} \mathrm{O}_{5}$ and $\mathrm{Sb}_{2} \mathrm{O}_{3}$ are $-75.3 \mathrm{kcal} / \mathrm{mol},-238.6 \mathrm{kcal} / \mathrm{mol}$, $-198.6 \mathrm{kcal} / \mathrm{mol},-137.7 \mathrm{kcal} / \mathrm{mol},-187.0 \mathrm{kcal} / \mathrm{mol}$ and $-151.5 \mathrm{kcal} / \mathrm{mol}$, respectively [23], [24]. Gibbs free energies of the ALD oxides are $-377.9 \mathrm{kcal} / \mathrm{mol},-260.1 \mathrm{kcal} / \mathrm{mol}$, $-211.0 \mathrm{kcal} / \mathrm{mol}$ and $-149.4 \mathrm{kcal} / \mathrm{mol}$ for $\mathrm{Al}_{2} \mathrm{O}_{3}, \mathrm{HfO}_{2}, \mathrm{TiO}_{2}$ and $\mathrm{ZnO}$ molecules, respectively [26]. This means that the formation of $\mathrm{Al}_{2} \mathrm{O}_{3}$ is energetically preferred due to lower Gibbs free energy of $\mathrm{Al}_{2} \mathrm{O}_{3}$ when compared with the competing surface oxides. $\mathrm{ZnO}$ and $\mathrm{TiO}_{2}$ also have higher Gibbs free energies than conductive native oxide $\mathrm{Ga}_{2} \mathrm{O}_{3}$. $\mathrm{Al}$ is in the same group in the periodic table with $\mathrm{In}$ and $\mathrm{Ga}$ atoms and $\mathrm{Al}_{2} \mathrm{O}_{3}$ has the same crystal structure with $\mathrm{In}_{2} \mathrm{O}_{3}$ and $\mathrm{Ga}_{2} \mathrm{O}_{3}$. Therefore $\mathrm{Al}_{2} \mathrm{O}_{3}$ is the best candidate for passivation among ALD oxides that we studied. ODT SAM seem also to clean surface oxides. Sulphur head of the ODT is chemically preferred over oxygen and replaces oxygen to form surface sulfides that are electrically less active then surface oxides. These may be called interfacial self-cleaning reactions of surface oxides with sulphur as determined by XPS measurements [25]. Finally, strong intermolecular interactions between long chains of ODT molecules form a closely packed and thermodynamically stable skin-like ultrathin protective layer. This method is as effective as $\mathrm{Al}_{2} \mathrm{O}_{3}$ passivation close to zero bias but for higher reverse bias voltages, trap assisted tunneling current dominates for ODT passivation and the dark current in this case diverges from $\mathrm{Al}_{2} \mathrm{O}_{3}$ dark current level. We believe that $2 \mathrm{~nm}$ thickness of ODT does not totally remove the traps from the ODT/SL surface. $\mathrm{SiO}_{2}$ is a standard passivation technique for superlattice infrared detector community. Its success is recurrently proven by different groups. Our results also confirm the success of $\mathrm{SiO}_{2}$ passivation. $\mathrm{Si}_{3} \mathrm{~N}_{4}$ passivation of superlattice photodetectors was demonstrated by Fuchs et.al. for the first time but the results obtained by other groups has not been favorable [16], [27] for InAs/GaSb system. Silicon nitride passivation showed the worse electrical results in our tests, as well. 


\section{CONCLUSION}

We have compared electrical performance of type-II superlattice photodetectors, designed for MWIR operation, passivated by different passivation techniques. We have used ALD deposited $\mathrm{Al}_{2} \mathrm{O}_{3}, \mathrm{HfO}_{2}, \mathrm{TiO}_{2}, \mathrm{ZnO}, \mathrm{PECVD}$ deposited $\mathrm{SiO}_{2}$, $\mathrm{Si}_{3} \mathrm{~N}_{4}$ and sulphur containing ODT SAM passivation layers on InAs/GaSb p-i-n superlattice photodetectors with cutoff wavelength at $5.1 \mu \mathrm{m}$. Dark current densities are measured as $3.3 \times 10^{-8} \mathrm{~A} / \mathrm{cm}^{2}, 3.9 \times 10^{-8} \mathrm{~A} / \mathrm{cm}^{2}, 2.2 \times 10^{-7} \mathrm{~A} / \mathrm{cm}^{2}$, $2.5 \times 10^{-6} \mathrm{~A} / \mathrm{cm}^{2}, 3.1 \times 10^{-5} \mathrm{~A} / \mathrm{cm}^{2}, 2.5 \times 10^{-4} \mathrm{~A} / \mathrm{cm}^{2}$, $7.3 \times 10^{-4} \mathrm{~A} / \mathrm{cm}^{2}$ and $1.3 \times 10^{-4} \mathrm{~A} / \mathrm{cm}^{2}$ for the $\mathrm{Al}_{2} \mathrm{O}_{3}, \mathrm{ODT}$, $\mathrm{SiO}_{2}, \mathrm{HfO}_{2}, \mathrm{TiO}_{2}, \mathrm{ZnO}, \mathrm{Si}_{3} \mathrm{~N}_{4}$ passivated and unpassivated diodes, respectively at $0.1 \mathrm{~V}$ reverse bias and $77 \mathrm{~K}$. These measurements yielded RA product values of $2.5 \times 10^{6} \Omega \mathrm{cm}^{2}$, $1.5 \times 10^{6} \Omega \mathrm{cm}^{2}, 3.6 \times 10^{5} \Omega \mathrm{cm}^{2}, 2.8 \times 10^{4} \Omega \mathrm{cm}^{2}$, $1.7 \times 10^{3} \Omega \mathrm{cm}^{2}, 3.1 \times 10^{2} \Omega \mathrm{cm}^{2}, 8.8 \times 10^{1} \Omega \mathrm{cm}^{2}$ and $5.7 \times 10^{2} \Omega \mathrm{cm}^{2}$ for the $\mathrm{Al}_{2} \mathrm{O}_{3}, \mathrm{ODT}, \mathrm{SiO}_{2}, \mathrm{HfO}_{2}, \mathrm{TiO}_{2}$, $\mathrm{ZnO}, \mathrm{Si}_{3} \mathrm{~N}_{4}$ passivated and unpassivated diodes, respectively at $-0.1 \mathrm{~V}$ bias. Temperature dependent dark current measurements showed that $\mathrm{Al}_{2} \mathrm{O}_{3}$ is at least an order of magnitude better than its closest competitor. This suggests that $\mathrm{Al}_{2} \mathrm{O}_{3}$ passivation reduces native oxides eliminating surface states and preventing current flow through the surface channel more efficiently. ODT and $\mathrm{SiO}_{2}$ show almost same performance at zero bias. $\mathrm{Si}_{3} \mathrm{~N}_{4}$ and $\mathrm{ZnO}$ passivation result in photodetectors that are worse than unpassivated photodetectors. This means that their deposition results in additional impurities and/or trap states at the surface. ALD deposited $\mathrm{HfO}_{2}$ and $\mathrm{TiO}_{2}$ is better than unpassivated detectors but they are not as good as $\mathrm{Al}_{2} \mathrm{O}_{3}$ passivation which is also deposited using the ALD system. Self cleaning mechanism of the surface oxides by ALD works better for $\mathrm{Al}_{2} \mathrm{O}_{3}$ passivation due to lower Gibbs free energy of aluminum oxides.

\section{REFERENCES}

[1] J. B. Rodriguez, E. Plis, G. Bishop, Y. D. Sharma, H. Kim, L. R. Dawson, and S. Krishna, " $n B n$ structure based on InAs/GaSb type-II strained layer superlattices," Appl. Phys. Lett., vol. 91, no. 4, pp. 043514-1-043514-8, Jul. 2007.

[2] P. Klipstein, O. Klin, S. Grossman, N. Snapi, I. Lukomsky, D. Aronov, M. Yassen, A. Glozman, T. Fishman, E. Berkowicz, O. Magen, I. Shtrichman, and E. Weiss, " $X B n$ barrier photodetectors based on InAsSb with high operating temperatures," Opt. Eng., vol. 50, no. 6, pp. 061002-1-061002-10, 2011.

[3] O. Salihoglu, A. Muti, K. Kutluer, T. Tansel, R. Turan, Y. Ergun, and A. Aydinli, "'N' structure for type-II superlattice photodetectors," Appl. Phys. Lett., vol. 101, no. 7, pp. 073505-1-073505-4, Aug. 2012.

[4] E. A. Plis, M. N. Kutty, and S. Krishna, "Passivation techniques for InAs/GaSb strained layer superlattice detectors," Laser Photon. Rev., vol. 7, no. 1, pp. 45-59, Jan. 2013.

[5] E. Plis, J. B. Rodriguez, S. J. Lee, and S. Krishna, "Electrochemical sulphur passivation of InAs/GaSb strain layer superlattice detectors," Electron. Lett., vol. 42, no. 21, pp. 1248-1249, Oct. 2006.

[6] A. Gin, Y. Wei, J. Bae, A. Hood, J. Nah, and M. Razeghi, "Passivation of type II InAs/GaSb superlattice photodiodes," Thin Solid Films, vols. 447-488, pp. 489-492, Jan. 2004.

[7] A. Hood, M. Razeghi, E. Aifer, and G. Brown, "Holographic scattering in photopolymer-dispersed liquid crystals," Appl. Phys. Lett., vol. 87, no. 15, pp. 151113-1-151113-3, Oct. 2005.

[8] Y. T. Kim, D. S. Kim, and D. H. Yoon, "PECVD $\mathrm{SiO}_{2}$ and $\mathrm{SiON}$ films dependant on the rf bias power for low-loss silica waveguide," Thin Solid Films, vol. 475, nos. 1-2, pp. 271-274, Mar. 2005.
[9] A. Hood, P. Y. Delaunay, D. Hoffman, M. Razeghi, and V. Nathan, "Near bulk-limited $\mathrm{R}_{0} \mathrm{~A}$ of long-wavelength infrared type-II InAs/GaSb superlattice photodiodes with polyimide surface passivation," Appl. Phys. Lett., vol. 90, no. 23, pp. 233513-1-233513-3, Jun. 2007.

[10] R. Rehm, M. Walter, F. Fuchs, J. Schmitz, and J. Fleissner, "Passivation of InAs/(GaIn) Sb short-period superlattice photodiodes with $10 \mu \mathrm{m}$ cutoff wavelength by epitaxial overgrowth with $\mathrm{Al}_{x} \mathrm{Ga}_{1-x} \mathrm{As}_{y} \mathrm{Sb}_{1-y}$," Appl. Phys. Lett., vol. 86, no. 17, pp. 173501-1-173501-3, Apr. 2005.

[11] O. Salihoglu, A. Muti, K. Kutluer, T. Tansel, R. Turan, and A. Aydinli, "Skin-like self-assembled monolayers on InAs/GaSb superlattice photodetectors," J. Phys. D, Appl. Phys., vol. 45, no. 36, p. 365102, Sep. 2012.

[12] O. Salihoglu, A. Muti, K. Kutluer, T. Tansel, R. Turan, and A. Aydinli, "Atomic layer deposited $\mathrm{Al}_{2} \mathrm{O}_{3}$ passivation of type II InAs/GaSb superlattice photodetectors," J. Appl. Phys., vol. 111, no. 7, pp. 074509-1-074509-4, Apr. 2012.

[13] C. J. Spindt, D. Liu, K. Miyano, P. L. Meissner, T. T. Chiang, T. Kendelewicz, I. Lindau, and W. E. Spicer, "Vacuum ultraviolet photoelectron spectroscopy of (NH4)2S-treated GaAs (100) surfaces," Appl. Phys. Lett., vol. 55, no. 9, pp. 861-863, Aug. 1989.

[14] D. Y. Petrovykh, J. C. Smith, T. D. Clark, R. Stine, L. A. Baker, and L. J. Whitman, "Self-assembled monolayers of alkanethiols on InAs," Langmuir, vol. 25, no. 20, pp. 12185-12194, Sep. 2009.

[15] J. C. Love, L. A. Estroff, J. K. Kriebel, R. G. Nuzzo, and G. M. Whitesides, "Self-assembled monolayers of thiolates on metals as a form of nanotechnology," Chem. Rev., Columbus, vol. 105, no. 4, pp. 1103-1170, 2005.

[16] M. Razeghi, Y. Wei, A. Gin, A. Hood, V. Yazdanpanah, M. Z. Tidrow, and V. Nathan, "High performance Type-II InAs/GaSb superlattices for mid, long, and very long wavelength infrared focal plane arrays," Proc. SPIE, vol. 5783, p. 86, Jun. 2005.

[17] O. Salihoglu, K. Kutluer, T. Tansel, R. Turan, C. Kocabas, and A. Aydinli, "Passivation of type II InAs/GaSb superlattice photodetectors with atomic layer deposited $\mathrm{Al}_{2} \mathrm{O}_{3}$," Proc. SPIE, vol. 8353, p. 83530Z, May 2012.

[18] C. L. McGuiness, A. Shaporenko, C. K. Mars, S. Uppili, M. Zharnikov, and D. L. Allara, "Molecular self-assembly at bare semiconductor surfaces: Preparation and characterization of highly organized octadecanethiolate monolayers on GaAs(001)," J. Amer. Chem. Soc., vol. 128, no. 15, pp. 5231-5243, Mar. 2006.

[19] A. Rogalski, J. Antoszewski, and L. Faraone, "Third-generation infrared photodetector arrays," J. Appl. Phys., vol. 105, no. 9, pp. 091101-1-091101-44, May 2009.

[20] D. Pulver, C. W. Wilmsen, D. Niles, and R. Kee, "Thermal oxides of $\mathrm{In}_{0.5} \mathrm{Ga}_{0.5} \mathrm{P}$ and $\mathrm{In}_{0.5} \mathrm{Al}_{0.5} \mathrm{P}, "$ J. Vac. Sci. Technol. B, Microelectron. Nanometer Struct., vol. 19, no. 1, pp. 207-214, Jan. 2001.

[21] A. Mang, K. Reimann, and S. Rubenacke, "Band gaps, crystal-field splitting, spin-orbit coupling, and exciton binding energies in $\mathrm{ZnO}$ under hydrostatic pressure," Solid State Commun., vol. 94, no. 4, pp. 251-254, Apr. 1995.

[22] T. Minami, T. Miyata, and J. Nomoto, "Impurity-doped $\mathrm{ZnO}$ thin films prepared by physical deposition methods appropriate for transparent electrode applications in thin-film solar cells," in Proc. IOP Conf. Ser., Mater. Sci. Eng., vol. 34. 2012, pp. 012001-1-012001-17.

[23] G. Hollinger, R. S. Kabbani, and M. Gendry, "Oxides on GaAs and InAs surfaces: An X-ray-photoelectron-spectroscopy study of reference compounds and thin oxide layers," Phys. Rev. B, vol. 49, no. 16, pp. 11159-11167, Apr. 1994.

[24] A. J. Bard, R. Parsons, and J. Jordan, Standard Potentials in Aqueous Solutions. New York, NY, USA: Marcel Dekker, 1985.

[25] D. Pulver, C. W. Wilmsen, D. Niles, and R. Kee, "Thermal oxides of $\mathrm{In}_{0.5} \mathrm{Ga}_{0.5} \mathrm{P}$ and $\mathrm{In}_{0.5} \mathrm{Al}_{0.5} \mathrm{P}, "$ J. Vac. Sci. Technol. B, Microelectron. Nanometer Struct., vol. 19, no. 1, pp. 207-214, Jan. 2001.

[26] C. L. Hinkle, A. M. Sonnet, E. M. Vogel, S. McDonnell, G. J. Hughes, M. Milojevic, B. Lee, F. S. Aguirre-Tostado, K. J. Choi, H. C. Kim, J. Kim, and R. M. Wallace, "GaAs interfacial selfcleaning by atomic layer deposition," Appl. Phys. Lett., vol. 92, no. 7, pp. 071901-1-071901-3, Feb. 2008.

[27] F. Fuchs, U. Weimer, W. Pletschen, J. Schmitz, E. Ahlswede, M. Walther J. Wagner, and P. Koidl, "High performance InAs/Ga ${ }_{1-x} \operatorname{In}_{x} \mathrm{Sb}$ superlattice infrared photodiodes," Appl. Phys. Lett., vol. 71, no. 22 pp. 3251-3253, Sep. 1997. 
Omer Salihoglu received the B.S. degree from Middle East Technical University, Ankara, Turkey, in 2001, and the Ph.D. degree from Temple University, Philadelphia, PA, USA, in 2009, both in physics. He is currently Post-Doctoral with Bilkent University, Ankara. His current research interests include superlattice infrared photodetector technologies, ultrafast crystallization of semiconductors, and graphene based plasmonics.

Abdullah Muti received the B.S. and M.Sc. degrees from Bilkent University, Ankara, Turkey, in 2010 and 2013, respectively, both in physics. He is currently pursuing the Ph.D. degree in physics with Bilkent University. His current research interests include MWIR/LWIR type-II superlattice superdetectors.
Atilla Aydinli received the M.S. and the Ph.D. degrees in engineering physics from the University of Virginia, Charlottesville, VA, USA, in $1980 . \mathrm{He}$ did postdoctoral work with Kansas State University, Manhattan, KS, USA, and joined Hacettepe University, Ankara, Turkey, in 1982. He became an Associate Professor in 1984. He was a Visiting Professor with the University of Padova, Padova, Italy, and University of Toledo, Toledo, OH, USA, before becoming a Full Professor in 1990. He was the Chairman with the Physics Department, Bilkent University, Ankara, from 1993 to 1997. He was a Fulbright Scholar with the University of California, Santa Barbara, CA, USA, in 1997. His current research interests include integrated optical devices, plasmonic cavities, nanocrystals, and IR superlattice photodetectors. He has been involved in numerous national and international projects. He is the author of over 130 peer reviewed journal articles. 